\section{The sense of smell in primary ciliary dyskinesia}

\author{
Joanne Rimmer
}

Olfactory dysfunction is common in chronic rhinosinusitis (CRS); indeed, it is one of the key diagnostic symptoms in both the European Position Paper on Rhinosinusitis ${ }^{1}$ and the American Clinical Practice Guidelines on Sinusitis. ${ }^{2}$ Objective evidence of hyposmia/anosmia has been reported in $30 \%-78 \%$ of patients with CRS, depending on which test is used. ${ }^{3}$ Subjective complaints of a loss of or reduction in the sense of smell have been shown to correlate well with objective measures. ${ }^{4}$ Loss of the sense of smell is an important symptom from a quality of life perspective and is known to correlate with depressive symptoms.

In inflammatory CRS, the cause of olfactory dysfunction is often multifactorial; nasal polyps are a physical barrier to odorant molecules reaching the olfactory epithelium, whereas oedematous mucosa also contributes to this 'conductive' problem. Motile cilia on the nasal epithelium may be impaired as a result of the disease process, as can the non-motile (primary) olfactory cilia on the specialised olfactory epithelium that are essential for initiation of the olfactory signalling cascade. ${ }^{5}$

Primary ciliary dyskinesia (PCD) is a congenital motile ciliopathy, associated with chronic sinusitis due to impaired mucociliary clearance. Pifferi et $a l^{6}$ hypothesise that olfactory function might be impaired in this condition due to primary ciliopathy affecting the olfactory cilia. There certainly seems to be growing

Correspondence to Dr Joanne Rimmer, Monash ENT Department, Moorabbin Hospital, Bentleigh East,

Victoria, VIC 3165, Australia; rimmer.joanne@gmail.com evidence of this in other ciliopathies. ${ }^{7}$ The idea is an interesting one and would certainly be useful to know from a clinical point of view, if only to better counsel patients as to the likelihood of improvement of this very important symptom with treatment.

This study found that patients with PCD were more likely to experience hyposmia and anosmia than their non-PCD sinusitis counterparts (74\% vs $24 \%$, respectively). Patients with PCD had significantly worse olfactory scores than non-PCD sinusitis patients, even taking into account the radiological severity of the sinus disease. The CT score has previously been shown to correlate well with the level of olfactory dysfunction, ${ }^{8}$ suggesting that in the patients with PCD there is an additional cause for their loss of smell. The fact that olfactory dysfunction was worse in patients with PCD with major ultrastructural abnormalities adds further support to this theory.

Patients with PCD seem to experience olfactory dysfunction more commonly and more severely than the general CRS population. It would seem worthwhile to obtain baseline smell measurements as routine in PCD clinics, using Sniffin' Sticks or a similar easy-to-use objective test, along with baseline lung function and hearing tests. Patients can then be counselled appropriately, which is so important when a symptom adversely affects quality of life as much as this one does.

Funding The authors have not declared a specific grant for this research from any funding agency in the public, commercial or not-for-profit sectors.
Competing interests None declared.

Patient consent Not required.

Provenance and peer review Commissioned; externally peer reviewed.

(C) Article author(s) (or their employer(s) unless otherwise stated in the text of the article) 2018. All rights reserved. No commercial use is permitted unless otherwise expressly granted.

D Check for updates

To cite Rimmer J. Thorax 2018;73:897.

Accepted 26 March 2018

Published Online First 7 April 2018

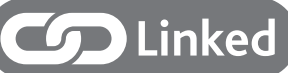

http://dx.doi.org/10.1136/thoraxjnl-2017-210661

Thorax 2018;73:897.

doi:10.1136/thoraxjnl-2018-211620

\section{REFERENCES}

1 Fokkens WJ, Lund VJ, Mullol J, et al. European position paper on rhinosinusitis and nasal polyps 2012. Rhinol Supp/ 2012;23:1-298.

2 Rosenfeld RM, Piccirillo JF, Chandrasekhar SS, et al. Clinical practice guideline (update): adult sinusitis. Otolaryngol Head Neck Surg 2015;152:S1-S39.

3 Kohli P, Naik AN, Harruff EE, et al. The prevalence of olfactory dysfunction in chronic rhinosinusitis. Laryngoscope 2017;127:309-20.

4 Mattos JL, Schlosser RJ, Storck KA, et al. Understanding the relationship between olfactory-specific quality of life, objective olfactory loss, and patient factors in chronic rhinosinusitis. Int Forum Allergy Rhinol 2017;7:734-40.

5 Jenkins PM, McEwen DP, Martens JR. Olfactory cilia: linking sensory cilia function and human disease. Chem Senses 2009;34:451-64.

6 Pifferi M, Bush A, Rizzo M, et al. Olfactory dysfunction is worse in primary ciliary dyskinesia compared with other causes of chronic sinusitis in children. Thorax 2018:73: 980-2.

7 Uytingco CR, Green WW, Martens JR. Olfactory loss and dysfunction in ciliopathies: Molecular mechanisms and potential therapies. Curr Med Chem 2018.

8 Saito T, Tsuzuki K, Yukitatsu Y, et al. Correlation between olfactory acuity and sinonasal radiological findings in adult patients with chronic rhinosinusitis. Auris Nasus Larynx 2016;43:422-8. 